\title{
Oceanic Forcing of Antarctic Climate Change: A Study Using a Stretched-Grid Atmospheric General Circulation Model
}

\author{
Gerhard Krinner, Chloé Largeron, And Martin Ménégoz \\ LGGE (CNRS and Université de Grenoble Alpes), Grenoble, France \\ CÉCILE Agosta \\ LGGE (CNRS and Université de Grenoble Alpes), Grenoble, France, and Department of Geography, \\ University of Liège, Liège, Belgium \\ Claire BRUTEL-VUILMET \\ LGGE (CNRS and Université de Grenoble Alpes), Grenoble, France
}

(Manuscript received 26 June 2013, in final form 3 March 2014)

\begin{abstract}
A variable-resolution atmospheric general circulation model (AGCM) is used for climate change projections over the Antarctic. The present-day simulation uses prescribed observed sea surface conditions, while a set of five simulations for the end of the twenty-first century (2070-99) under the Special Report on Emissions Scenarios (SRES) A1B scenario uses sea surface condition anomalies from selected coupled ocean-atmosphere climate models from phase 3 of the Coupled Model Intercomparison Project (CMIP3). Analysis of the results shows that the prescribed sea surface condition anomalies have a very strong influence on the simulated climate change on the Antarctic continent, largely dominating the direct effect of the prescribed greenhouse gas concentration changes in the AGCM simulations. Complementary simulations with idealized forcings confirm these results. An analysis of circulation changes using self-organizing maps shows that the simulated climate change on regional scales is not principally caused by shifts of the frequencies of the dominant circulation patterns, except for precipitation changes in some coastal regions. The study illustrates that in some respects the use of bias-corrected sea surface boundary conditions in climate projections with a variable-resolution atmospheric general circulation model has some distinct advantages over the use of limited-area atmospheric circulation models directly forced by generally biased coupled climate model output.
\end{abstract}

\section{Introduction}

Coupled ocean-atmosphere climate model (hereafter simply "coupled climate model") projections indicate increasingly positive surface mass balance (SMB) for the Antarctic ice sheet as a whole for the twenty-first century. The projected accumulation increase, induced by a higher moisture holding capacity of the atmosphere directly linked to warmer air temperatures, tends to overcompensate for increased surface melt rates that are simulated at the ice sheet margins (e.g., Gregory and

Corresponding author address: Gerhard Krinner, LGGE/CNRS, 54 rue Molière, BP 96, 38402 Saint Martin d'Hères CEDEX, France.

E-mail: krinner@lgge.obs.ujf-grenoble.fr
Huybrechts 2006; Krinner et al. 2007; Church et al. 2013). Several recent studies (e.g., Bracegirdle et al. 2008; Uotila et al. 2007; Krinner et al. 2008; Vizcaino et al. 2008, 2010; Agosta et al. 2013; Ligtenberg et al. 2013) confirm the sign of earlier projections of future Antarctic SMB changes. This lead the Intergovernmental Panel on Climate Change (IPCC) to estimate that over the twentyfirst century, the Antarctic SMB change would induce a global eustatic sea level decrease of between $0.02 \pm$ $0.02 \mathrm{~m}$ for the low-range representative concentration pathway (RCP) 2.6 scenario and $0.04 \pm 0.03 \mathrm{~m}$ for the high-range RCP8.5 scenario, with similar values for the older midrange Special Report on Emissions Scenarios (SRES) A1B scenario (Church et al. 2013; their Table 13.5). However, although the sign of the contribution of 
the Antarctic SMB to future sea level changes appears fairly certain, its amplitude is poorly constrained and thus constitutes a large source of uncertainty in sea level change projections. For instance, Krinner et al. (2008) and Genthon et al. (2009) reported that climate models with finer horizontal resolution tend to predict a larger precipitation increase over the next century. This is linked to the fact that about three-quarters of the continental-average precipitation rise originates from the marginal regions of the Antarctic ice sheet with surface elevation below $2250 \mathrm{~m}$ (Genthon et al. 2009). Moreover, present and potential future ablation areas are also confined to the ice sheet marginal areas. Bengtsson et al. (2011) reported that the simulated ablation increase over the next century may also be strongly resolution dependent, with simulated ablation increasing with horizontal model resolution. For these reasons, high-resolution climate model simulations or downscaling techniques are required to increase the reliability of the range of projected future Antarctic SMB changes.

Here, we use an atmospheric general circulation model (AGCM) with regionally high resolution to produce a set of simulations of the Antarctic climate and SMB during selected periods of the twenty-first century. We prescribe anthropogenic forcing following the SRES A1B scenario and sea surface conditions (SSC; sea surface temperature and sea ice fraction) using the oceanic output of coupled ocean-atmosphere climate projection runs from phase 3 of the Coupled Model Intercomparison Project (CMIP3). Following Krinner et al. (2008), we use an anomaly method for prescribing these oceanic boundary conditions. The anomaly method allows using observed oceanic boundary conditions for the present. This clearly improves the representation of the present climate in the atmosphere-only control simulation. Moreover, systematic biases of oceanic boundary conditions from a coupled climate model are not imported into the atmosphere-only climate change projection when an anomaly method is used. Krinner et al. (2008) argue that this should also increase the confidence in the simulation of the future climate. In this respect, it is noteworthy that the use of anomaly methods was proposed in phase 5 of CMIP (CMIP5) atmosphere-only experiments (Taylor et al. 2009).

A question that arises when designing an atmosphereonly climate change experiment is this: How sensitive will the projected climate be to the choice of the oceanic boundary conditions? In particular, given that CMIP3 climate change experiments were carried out with about 20 different climate models, how important is the choice of the coupled climate model from which the SSC change signal is taken? This question clearly warrants assessment. In principle, the anomaly method should reduce the impact of the choice because the climate change signal is generally supposed to be somewhat less model dependent. In the particular case of Antarctica, it was shown that the climate variability of this region on the interannual scale is rather decoupled from oceanic forcing (Connolley 1997; Krinner et al. 2008). However, the average ocean forcing is clearly of importance for the Antarctic climate, most notably in the coastal regions (Krinner et al. 2008). One might speculate that this is less the case in the plateau regions because the nearsurface temperature inversion, particularly in winter, could confine the effect of oceanic changes to the lower atmosphere around the Antarctic coast, similar to what has been reported for the Arctic as a response to reduced sea ice concentration (Deser et al. 2010). But because the coastal regions are critical for future continental SMB changes (Krinner et al. 2007), prescribed SSTs are certainly critical boundary conditions for atmosphere-only climate change simulations.

In this work we extend the work by Krinner et al. (2008) by using SSC anomalies from five coupled climate models to evaluate in detail the role of imposed SSC anomalies taken from different coupled climate model simulations in projections of twenty-first century Antarctic climate change with one AGCM at fairly high horizontal resolution. We focus in particular on the relative impact of the choice of oceanic boundary conditions in the ice sheet's marginal and central regions, and on the influence of these boundary conditions on simulated near-surface climate (more specifically on circulation patterns, surface air temperature, and precipitation). We furthermore discuss the meaning of these results for Antarctic climate projection downscaling experiments in general.

\section{Data and methods}

\section{a. Design of the simulations}

We used version 4 of the Laboratoire de Météorologie Dynamique-Zoom (LMDZ) AGCM (Hourdin et al. 2006) that includes several improvements for the simulation of polar climates as suggested by Krinner et al. (1997). The model was run with 19 vertical levels and $144 \times 109$ (longitude $\times$ latitude) horizontal grid points. These are regularly spaced in longitude and irregularly spaced in latitude. The spacing is such that the meridional resolution is about $60 \mathrm{~km}$ in the region of interest southward of the polar circle. Because of the convergence of the meridians, the zonal resolution increases near the pole $(80 \mathrm{~km}$ at the polar circle and below $60 \mathrm{~km}$ south of $77^{\circ} \mathrm{S}$ ) in spite of the relatively low number of zonal grid points. This is the same grid as that used by Krinner et al. (2007, 2008), and the same model version 
TABLE 1. Boundary conditions imposed for the simulations carried out for this study (see text).

\begin{tabular}{lcll}
\hline \hline Simulation & Atmospheric composition & SSC period & \multicolumn{1}{c}{ Prescribed SSC } \\
\hline E20 & $1979-2007$ & $1979-2007$ & HadISST \\
E21 & $2070-99$ & $2070-99$ & HadISST + MPI-ECHAM5 anomalies \\
E21 & $2070-99$ & $2070-99$ & HadISST + ISPL-CM4 anomalies \\
E21 & $2070-99$ & $2070-99$ & HadISST + CNRM-CM3 anomalies \\
E21 & $2070-99$ & $2070-99$ & HadISST + MIROC3.2(hires) anomalies \\
E21 & $2070-99$ & $2070-99$ & HadISST + HadCM3 anomalies \\
$S_{\text {SSC20 }}+$ RF20 & $1979-2007$ & $1979-2007$ & HadISST \\
$S_{S S 20}+$ RF21 & $2070-99$ & $1979-2007$ & HadISST \\
$S_{S S C 21+R F 20}$ & $1979-2007$ & $2070-99$ & HadISST + MIROC3.2(hires) anomalies \\
S $_{S S C 21+\text { RF21 }}$ & $2070-99$ & $2070-99$ & HadISST + MIROC3.2(hires) anomalies \\
\hline
\end{tabular}

as that used by Krinner et al. (2008), who evaluated the model performance.

We carried out one present-day (1979-2007) reference simulation using, as principal time-dependent boundary conditions of interest here, global analyses of sea ice concentration and sea surface temperature from the Hadley Centre Global Sea Ice and Sea Surface Temperature dataset (HadISST; Rayner et al. 2003) and observed greenhouse gas concentrations $\left[\mathrm{CO}_{2}, \mathrm{CH}_{4}\right.$, $\mathrm{N}_{2} \mathrm{O}$, chlorofluorocarbon(CFC)11, CFC12]. A series of simulations for 2070-99 were carried out using greenhouse gas concentrations following the A1B scenario (Nakicenovic et al. 2000) and prescribed SSC following the anomaly method described in detail by Krinner et al. (2008). This anomaly method essentially consists of adding SSC anomalies (i.e., sea surface temperature and sea ice concentration changes) from a coupled model climate change experiment to observed present (19792007) SSC. A single present-day reference simulation can be used for a set of future climate simulations using SSC from different coupled climate simulations. This present-day reference simulation is referred to as E20 (for "end of the twentieth century").

A slightly different approach could in principle be to apply the same constant correction to sea ice concentration and sea surface temperatures from a coupled climate model both for the present-day and future simulations. In this case, one present-day simulation would need to be carried out for each forcing coupled climate model (because the interannual variability for the present would be taken from the forcing coupled climate model, not from the observed data). This would increase the computational requirements, but it would also provide the possibility to evaluate the effect of simulated changes in interannual variability.

The SSC anomalies for the future simulations are taken from CMIP3 coupled model SRES A1B scenario climate change experiments available from the IPCC Data Distribution Centre (http://www.ipcc-data.org/). These anomalies are calculated for the means of the two periods 1980-2007 and 2070-99. We use the SSC anomalies from the first ensemble runs of the Centre National de Recherches Météorologiques Coupled Global Climate Model, version 3 (CNRM-CM3); Max Planck Institute-ECHAM5 (MPI-ECHAM5); L'Institut Pierre-Simon Laplace Coupled Model, version 4 (IPSL-CM4); Hadley Centre Coupled Model, version 3 (HadCM3); and Model for Interdisciplinary Research on Climate, version 3.2 (high resolution) [MIROC3.2 (hires)]. These models cover a fairly large range of transient climate responses (the change in the global surface temperature, averaged over a 20 -yr period, centered around the time of atmospheric carbon dioxide doubling in a $1 \% \mathrm{yr}^{-1}$ compound carbon dioxide increase experiment) from $1.6^{\circ} \mathrm{C}$ for CNRM-CM3 to $2.6^{\circ} \mathrm{C}$ for MIROC3.2(hires) (Randall et al. 2007). We thus have five simulations, differing by the imposed SSC anomalies, for 2070-99. These simulations are called E21 $x_{x}$ (for "end of the twenty-first century," with $x$ standing for the coupled climate model from which the SSC anomalies were obtained). The first year of each simulation (E20 and E21 $1_{x}$ ) is discarded as spinup. In addition, the E21 $x$ simulations were initialized from a transient run covering the years 2008-69; in this transient run, HadCM3 SSC anomalies were used. This spinup procedure (including the start from a transient climate change simulation for the E21 $1_{x}$ runs) allows for a consistent initialization of slowly reacting parts of the simulated system, in particular the snow cover. Table 1 lists the different simulations used in this work.

We carried out supplementary simulations aiming at analyzing in more detail the separate effects of changes of direct instantaneous radiative forcing on one hand and SSC changes on the other hand. Unfortunately, these simulations had to be done with a slightly more recent version of LMDZ because of a modified computer architecture. Therefore we also had to carry out a supplementary control simulation. These supplementary simulations were done using present-day observed SSC with and without the MIROC3.2(hires) SSC 
anomalies, and alternatively with greenhouse gas concentrations for the end of the twentieth or for the end of the twenty-first centuries, as in the E20 and E21 simulations. This yields four possible combinations for the boundary conditions for these supplementary simulations. The four supplementary simulations are referred to as $\mathrm{S}_{\mathrm{SSC} 20+\mathrm{RF} 20}, \mathrm{~S}_{\mathrm{SSC} 20+\mathrm{RF} 21}, \mathrm{~S}_{\mathrm{SSC} 21+\mathrm{RF} 20}$, and $\mathrm{S}_{\mathrm{SSC} 21+\mathrm{RF} 21}$, with the subscripts indicating the combination of prescribed boundary conditions used. Simulation $\mathrm{S}_{\mathrm{SSC} 20+\mathrm{RF} 20}$ is the supplementary control simulation mentioned above. Simulation $\mathrm{S}_{\mathrm{SSC} 21+\mathrm{RF} 21}$ is equivalent to the simulation E21 $1_{\text {MIROC. }}$ The simulated climate change from $\mathrm{S}_{\mathrm{SSC} 20+\mathrm{RF} 20}$ to $\mathrm{S}_{\mathrm{SSC} 21+\mathrm{RF} 21}$ differs slightly from the change from E20 to E21 $1_{\text {MIROC }}$ because a more recent model version has been used in the supplementary simulations, as well as because of internal atmospheric variability.

\section{b. Prescribed sea surface conditions}

The monthly mean hemispheric sea ice areas for the present (1979-2007) and the period 2070-99 as prescribed in the different simulations are shown in Fig. 1. The contrasting shape of the sea ice area in summer in E21 ${ }_{\text {CNRM }}$ is due to a substantial sea ice area bias of the CNRM-CM3 coupled climate model during that season in the present-day control simulation. Because presentday summer sea ice area in the Southern Hemisphere in that simulation is extremely low, almost no change occurs between the present and the end of the twenty-first century in January and February. Our anomaly algorithm therefore yields present-day summer sea ice area for these months at the end of the twenty-first century in E21 $1_{\text {CNRM. }}$. Apart from this artefact of the anomaly method caused by overly strong biases of the original data, the seasonal cycles of the prescribed sea ice cover in the different projections are of fairly similar shape. However, the amplitude of sea ice area reduction clearly

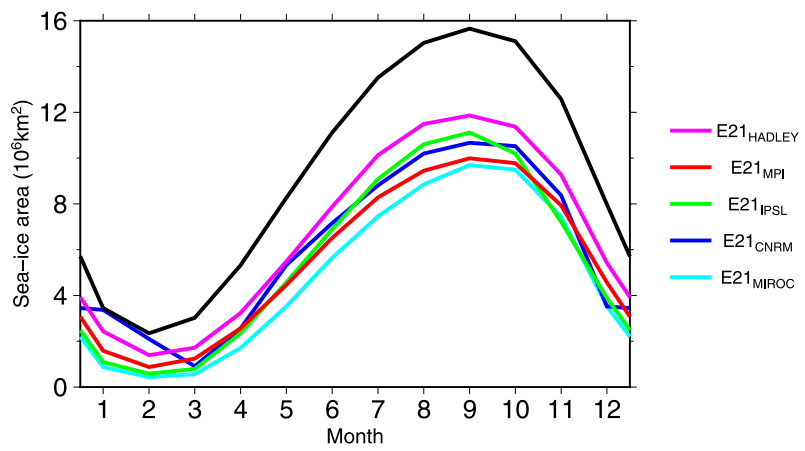

FIG. 1. Prescribed Southern Hemisphere sea ice cover. The 1980-2007 reference simulation E20 (black) and 2070-2100 SRES A1B simulations with SSC anomalies from different coupled models: $\mathrm{E} 21_{\mathrm{MPI}}$ (red), E21 $1_{\text {IPSL }}$ (green), E21 $1_{\mathrm{CNRM}}$ (blue), E21 $1_{\text {MIROC }}$ (aqua), and E21 HADLEY (pink).

depends on the coupled climate models used. The reduction of the maximum (generally September) sea ice areas varies between $24 \%$ in E21 HADLEY and $38 \%$ in E21 1 MIROC. In the annual mean, the reduction varies from $30 \%$ in in $\mathrm{E} 21_{\mathrm{HADLEY}}$ to $48 \%$ in $\mathrm{E} 21_{\mathrm{MIROC}}$.

Strong differences exist in the oceanic surface temperature forcing among the various E21 simulations. This is an obvious consequence of different climate sensitivities of the respective coupled climate models used as a basis for the construction of the sea surface boundary conditions for our model runs, and of different regional-scale climate change patterns in these different coupled simulations. The prescribed SST change is much stronger in E21 $1_{\mathrm{MIROC}}$ than in the other E21 simulations (Table 2). The annual-mean surface air temperature (SAT) change (Fig. 2) can be used to visualize the average SST forcing used in the E21 simulations over the ice-free parts of the oceans, since surface temperature and 2-m air temperature are fairly similar there. Over the ocean close to the Antarctic coast, the strong air

TABLE 2. Prescribed and simulated annual-mean changes over the Southern Ocean (SO: south of $50^{\circ} \mathrm{S}$ ) and the Antarctic continent (AA). Columns are as listed: $\Delta T_{\mathrm{SO}}$, prescribed surface temperature change over the perennially ice-free areas (sea ice concentration always $<5 \%$ ) of the Southern Ocean $\left({ }^{\circ} \mathrm{C}\right) ; \Delta \mathrm{SIE}_{\mathrm{SO}}$, prescribed change in annual-mean sea ice extent $(\%) ; \Delta T_{\mathrm{AA}}$, simulated annual-mean surface air temperature change $\left({ }^{\circ} \mathrm{C}\right.$ ) over Antarctic land grid points (land fraction $>80 \%$ ); $\Delta P_{\mathrm{AA}}$, simulated annual-mean precipitation change (\%, relative to E20) over Antarctic land grid points (land fraction $>80 \%$ ); and $\beta=\Delta P_{\mathrm{AA}} /\left(P_{\mathrm{AA}} \Delta T_{\mathrm{AA}}\right)$, simulated sensitivity of Antarctic precipitation to temperature change $\left(\%{ }^{\circ} \mathrm{C}^{-1}\right)$. All values are relative to the E20 averages for the E21 simulations and relative to the $\mathrm{S}_{\mathrm{SSC} 20+\mathrm{RF} 20}$ averages for the supplementary simulations $\mathrm{S}_{\mathrm{SSC} 21+\mathrm{RF} 20}, \mathrm{~S}_{\mathrm{SSC} 20+\mathrm{RF} 21}$, and $\mathrm{S}_{\mathrm{SSC} 21+\mathrm{RF} 21}$.

\begin{tabular}{|c|c|c|c|c|c|}
\hline Simulation & $\Delta T_{\mathrm{SO}}\left({ }^{\circ} \mathrm{C}\right)$ & $\Delta \operatorname{SIE}_{\mathrm{SO}}(\%)$ & $\Delta T_{\mathrm{AA}}\left({ }^{\circ} \mathrm{C}\right)$ & $\Delta P_{\mathrm{AA}}(\%)$ & $\beta\left(\%{ }^{\circ} \mathrm{C}^{-1}\right)$ \\
\hline $\mathrm{E} 21_{\mathrm{MPI}}$ & 0.85 & -40.70 & 2.69 & 13.70 & 5.10 \\
\hline E21 IPSL & 0.82 & -39.70 & 2.71 & 15.90 & 5.87 \\
\hline $\mathrm{E} 21_{\mathrm{CNRM}}$ & 0.80 & -35.20 & 2.91 & 11.80 & 5.93 \\
\hline E21 $1_{\text {HADLEY }}$ & 1.21 & -30.40 & 2.91 & 14.00 & 4.81 \\
\hline E21 $1_{\text {MIROC }}$ & 2.24 & -47.80 & 4.70 & 29.60 & 6.30 \\
\hline $\mathrm{S}_{\mathrm{SSC} 21+\mathrm{RF} 21}$ & 2.18 & -45.50 & 4.19 & 30.4 & 7.26 \\
\hline $\mathrm{S}_{\mathrm{SSC} 21+\mathrm{RF} 20}$ & 2.18 & -45.50 & 4.18 & 28.1 & 6.72 \\
\hline $\mathrm{S}_{\mathrm{SSC} 20+\mathrm{RF} 21}$ & 0 & 0 & 0.49 & -0.14 & $(-0.28)$ \\
\hline
\end{tabular}




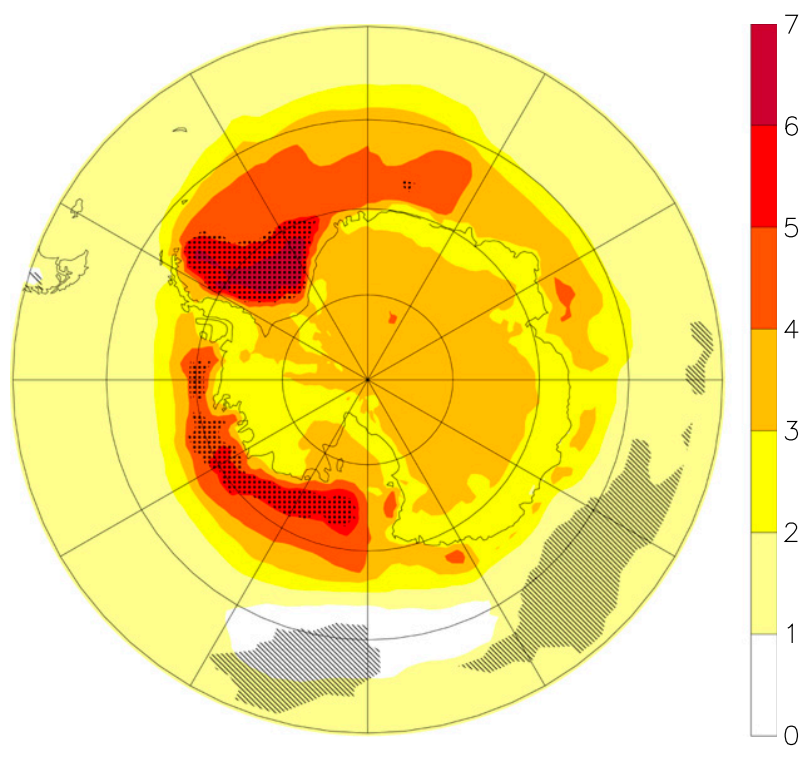

Annual mean SAT E21-E20

FIG. 2. Simulated annual-mean SAT changes [2070-99 minus 1980-2007 $\left({ }^{\circ} \mathrm{C}\right)$, average over all 5 E21 simulations]. Stippling identifies regions where SAT increase is in excess of $4^{\circ} \mathrm{C}$ in at least 4 out of 5 E21 simulations and hatching indicates regions where SAT increase is less than $1^{\circ} \mathrm{C}$ in at least 4 out of $5 \mathrm{E} 21$ simulations.

temperature increase visible in Fig. 2 is a direct consequence of the prescribed sea ice cover decrease.

\section{c. SOM analysis}

We use the self-organizing map (SOM) algorithm (Kohonen 2001) to identify the most representative synoptic situations in our simulations. This method is based on an unsupervised learning process that allows identifying general patterns in high-dimensional input data. The SOM algorithm has been shown to be suitable to study atmospheric circulation, in particular in the polar regions (Cassano et al. 2006; Uotila et al. 2007). Here it is applied to daily sea level pressure (SLP) output of our reference simulation E20 in order to identify the $25(5 \times 5)$ most representative synoptic patterns over the Southern Ocean. Based on daily SLP anomalies, each day of each of our simulations is then attributed to one of the 25 identified representative patterns. The chosen number of representative circulation patterns results from a compromise between the need to have a reasonable similarity between the individual daily SLP maps and the identified representative patterns on one hand and the need to obtain physically and quantitatively meaningful results on the other hand. Tests with varying numbers of prescribed representative situations showed that the results do not depend critically on this number. Mean SLP, precipitation, and temperature maps for the entire Antarctic and Southern Ocean region are then calculated separately for each of the 25 identified situations and for each simulation by averaging the corresponding variable for all days attributed to the corresponding representative situation. The average of an atmospheric variable $V$ (precipitation, surface pressure, etc.) for a given simulation can then be written as $V=\sum_{i=1}^{N} f_{i} v_{i}$, where $N=25, v_{i}$ is the average of $V$ for each of the identified representative circulation patterns, and $f_{i}$ is its probability of occurrence (e.g., in number of days per year). The average change of $V$ between the end of the twentieth and twenty-first centuries can then be written as

$$
\begin{aligned}
\Delta V & =\sum_{i=1}^{N} f_{i, 21} v_{i, 21}-\sum_{i=1}^{N} f_{i, 20} v_{i, 20} \\
& =\sum_{i=1}^{N}\left(f_{i, 20}+\Delta f_{i}\right)\left(v_{i, 20}+\Delta v_{i}\right)-\sum_{i=1}^{N} f_{i, 20} v_{i, 20} \\
& =\sum_{i=1}^{N} f_{i, 20} \Delta v_{i}+\sum_{i=1}^{N} v_{i, 20} \Delta f_{i}+\sum_{i=1}^{N} \Delta f_{i} \Delta v_{i} .
\end{aligned}
$$

Following Uotila et al. (2007), the term $\Delta_{\mathrm{th}} V=$ $\left(\sum_{i=1}^{N} f_{i, 20} \Delta v_{i}\right)$ will be called the thermodynamical contribution of the average change of $V$ in the following, and the term $\Delta_{d} V=\left(\sum_{i=1}^{N} v_{i, 20} \Delta f_{i}\right)$ will be called the dynamical contribution. The thermodynamical contribution $\Delta_{\mathrm{th}} V$ represents the effect of the change of $V$ for all individual representative synoptic situations. In the case of precipitation, $\Delta v_{i}$ is typically due to a modified moisture holding capacity of the air resulting from average temperature changes. This is the reason for the term "thermodynamical." For consistency, we apply this name also to the case of surface pressure. The dynamical contribution $\Delta_{d} V$ represents the effect of changes of the frequencies of the representative synoptic situations. The second-order term $\sum_{i=1}^{N} \Delta f_{i} \Delta v_{i}$ is usually negligible (Uotila et al. 2007). This is also the case in our simulations. Concerning precipitation, we will quantify the dynamical and thermodynamical fractions of the total change $f_{d}=\Delta_{d} V / \Delta V$ and $f_{\text {th }}=\Delta_{\text {th }} V / \Delta V$ because of the large precipitation gradients between the coastal regions and the interior of the ice sheet.

\section{Results}

\section{a. Continental-scale temperature and precipitation changes}

On the continental scale, there is a clear link between the prescribed SSC (the only difference among the setups of the various E21 simulations) and the Antarctic surface climate simulated by LMDZ, as can be seen in Table 2 and 
a)

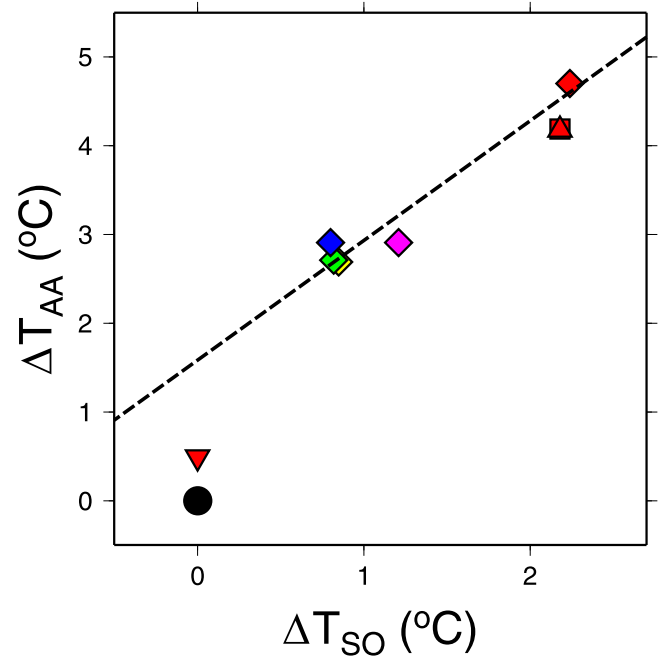

b)

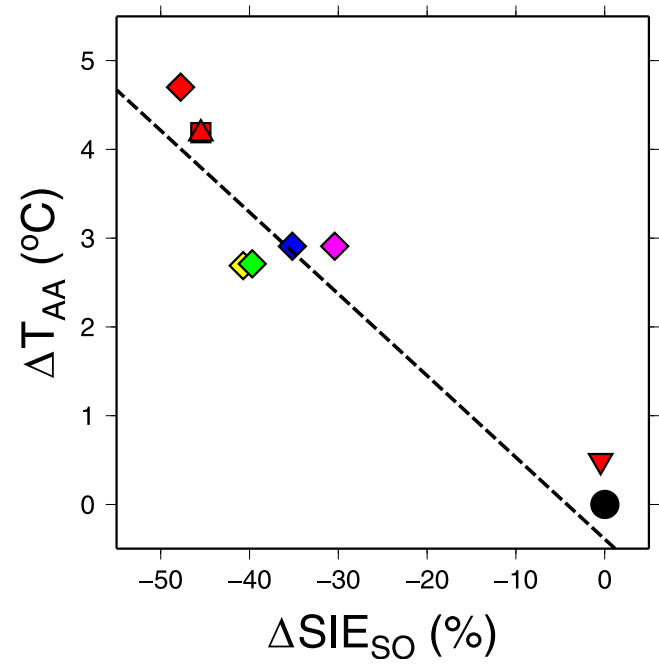

c)

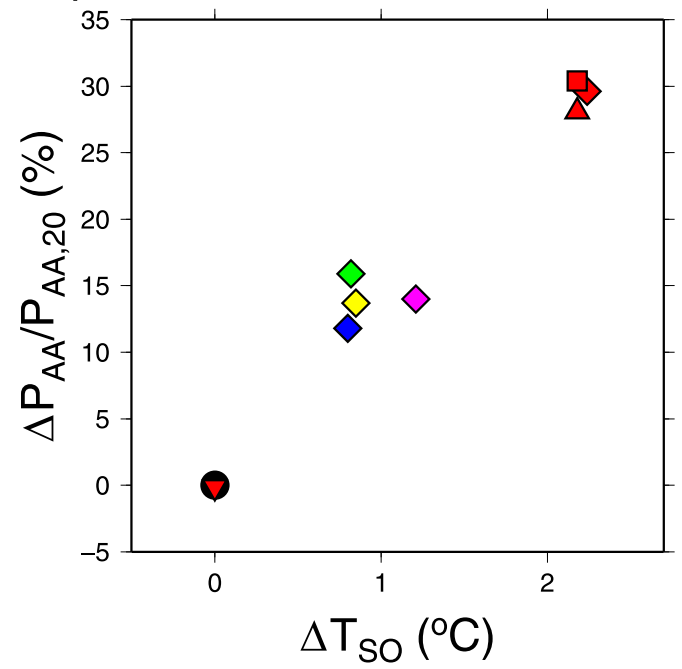

d)

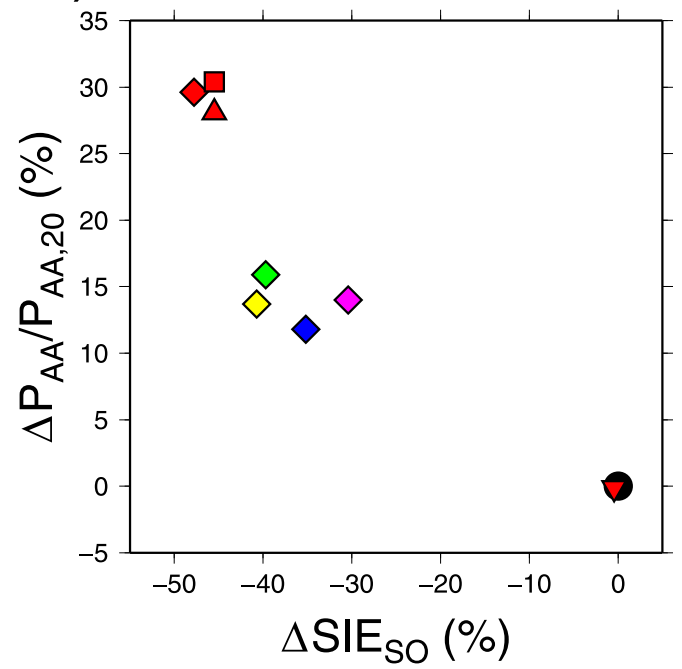

FIG. 3. Relationship between prescribed SSC change and simulated continental mean Antarctic climate change. Variable names and definitions are the same as in Table 2. Diamonds represent the E21 simulations [ E21 IPSL (green),

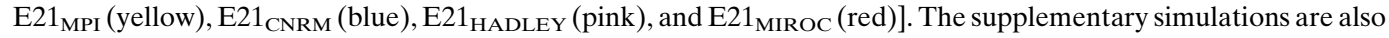
indicated in red $\left[\mathrm{S}_{\mathrm{SSC} 21+\mathrm{RF} 21}\right.$ (red square), $\mathrm{S}_{\mathrm{SSC} 21+\mathrm{RF} 20}$ (red triangle), and $\mathrm{S}_{\mathrm{SSC} 20+\mathrm{RF} 21}$ (inverted red triangle)]. Values for E20 and $\mathrm{S}_{\mathrm{SSC} 20+\mathrm{RF} 20}$ are 0 on both axes by construction and indicated by a filled black circle. The dotted lines are linear regressions calculated using the E21 points only [i.e., taking into account neither the E20 point at $(0,0)$ nor the supplementary simulations].

Fig. 3. Indeed, Fig. 3 shows that simulated temperature and precipitation changes appear to be tightly linked to the amplitude of the prescribed change of the oceanic boundary conditions, and in particular almost proportional to the prescribed change of sea ice extent (diamonds in Fig. 3; please note that the regression lines in Fig. 3 are calculated using only the simulations designated by diamonds). This relationship for the different E21 simulations is essentially due to the prescribed E2 $1_{\text {MIROC }}$ Southern Ocean SSC change over the twenty-first century, which is much stronger than for the other E21 simulations.
Because of an obvious and physically justified intermodel link between Southern Ocean SST and sea ice concentration changes $\left(r^{2}=0.60\right)$, the simulated Antarctic temperature and precipitation respond to both forcings similarly.

\section{b. Circulation changes}

The simulated annual-mean SLP changes (Fig. 4b) are, consistently for all E21 simulations, characterized by a ternary structure with maximum SLP decrease over the Southern Ocean at about $30^{\circ} \mathrm{W}, 60^{\circ} \mathrm{E}$, and $180^{\circ}$ and slight 


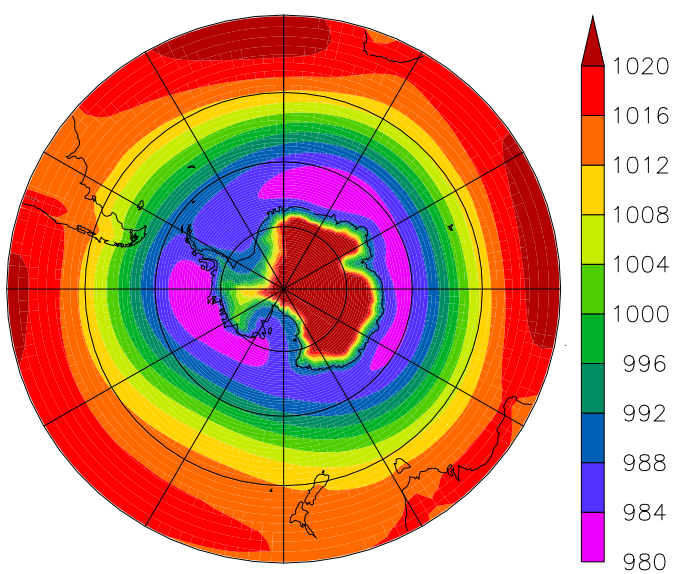

a) Annual mean SLP E20

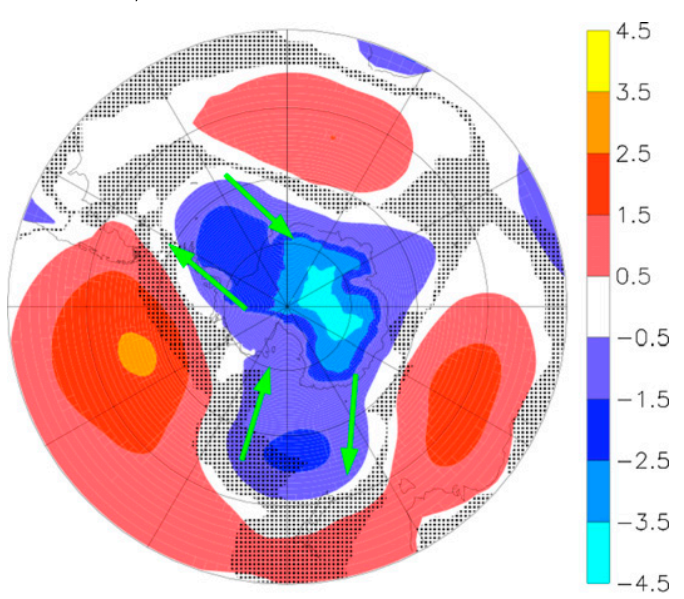

b) Annual mean SLP E21-E20

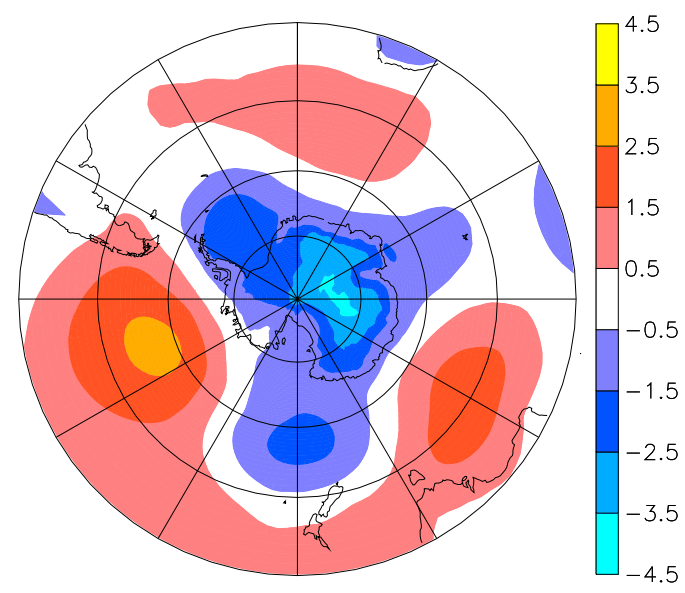

c) Thermodynamical part of annual mean SLP E21 - E20

FIG. 4. Simulated annual-mean SLP and its changes (average over all E21 simulations): (a) present-day annual-mean SLP as simulated in E20 (hPa), (b) E21 minus E20 (hPa), and (c) thermodynamical contribution $\Delta_{\text {th }}$ to the total SLP change E21 minus E20. In (b), stippling identifies regions where SLP change has the same sign in less than 4 out of 5 E21 simulations; also, green arrows indicate the direction of the differential geostrophic flow induced by the seal-level pressure change. pressure increase in between. Closer to the Antarctic, and again consistently, pressure decrease is clearly dominant. At present, pressure ridges are simulated at the longitudes of maximum future pressure decrease (Fig. 4a). This means that the ternary structure of pressure changes is such that it increases the zonality of SLP and thus of the atmospheric circulation around the Antarctic. This is consistent with projected Southern Hemisphere circulation pattern changes reported in previous studies (e.g., Shindell and Schmidt 2004).

The frequencies of the typical circulation patterns obtained using the SOM method applied to the daily SLP distributions from the E20 simulation (Fig. 5) do not change in a very consistent manner across all E21 simulations, as can be seen in Fig. 6: For some situations, there is a large spread among the individual E21 simulations in terms of the amplitude and even sign of the simulated frequency changes. Moreover, the average SLP change (Fig. 4b) cannot be easily traced back to an increase of the frequency of a particular group of synoptic situations given in Figs. 5 and 6. In particular, there is no increase of the frequency of situation 14 in Fig. 5, although this anomaly closely resembles the average SLP change over the twenty-first century (Fig. 4b). The SLP change is indeed almost entirely due to the thermodynamical contribution, as can be seen from the strong similarity of Figs. 4b and $4 c$. This means that the average SLP change is not a consequence of the combined changes of the frequencies of the individual typical synoptic situations, but rather a consequence of changes of the average pressure anomaly of each of the individual typical synoptic situations.

\section{c. Precipitation changes: Annual means}

Along the ice sheet margins, there is a distinct tendency for particularly strong precipitation increase in the sectors where stationary circulation changes (Figs. 4 and 7) lead to increased advection of oceanic air (and thus moisture) toward the Antarctic continent. Conversely, Figs. 4 and 7 show that the coastal precipitation change is weak (but still generally positive) in the areas where the average circulation change induces more advection of cold and dry air from the interior (indicated by green arrows in Fig. 4b). This suggests that the patterns of precipitation change in the coastal regions of Antarctica can be understood essentially in terms of stationary circulation changes. However, the spatial pattern of relative precipitation change in the coastal areas is not totally consistent among the different E21 simulations except for regions where the absolute precipitation change is strong. This is linked to the prescribed spatial patterns of sea ice concentration and sea surface temperature change, which vary among these simulations and induce different circulation changes 

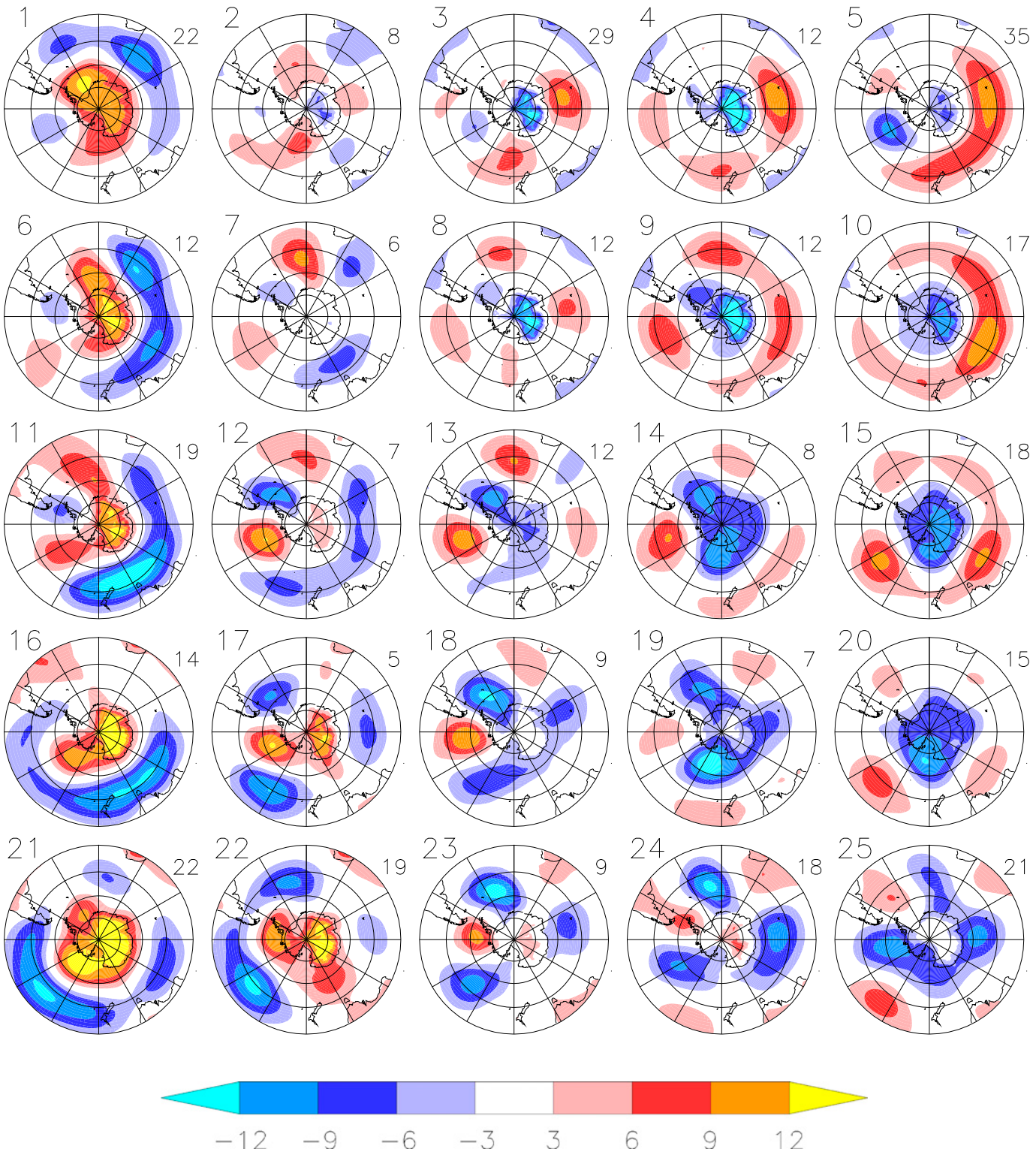

FIG. 5. SLP anomalies (hPa) for the 25 SOMs identified using the 28 years of daily SLP maps from the E20 simulation. In the following, each meteorological situation is referred to using the number indicated on the top left of the corresponding map. The small number on the top right of each map indicates the frequency (day $\mathrm{yr}^{-1}$ ) of the corresponding meteorological situation in the present-day simulation E20.

over the Southern Ocean, as illustrated in Fig. 8, which displays the simulated annual-mean surface air temperature, SLP, and precipitation changes for two selected E21 simulations (E21 IPSL and E21 $1_{\text {HADLEY }}$ ). The oceanic surface temperature forcing is either direct through the prescribed sea surface temperature or more indirect through the prescribed sea ice concentration. Over the ice-free ocean, the simulated surface air temperature change is tightly constrained by, and very close to, the prescribed sea surface temperature change. The large-scale patterns of change in E21 IPSL and
E21 HADLEY are broadly similar. However, some clear differences in this surface forcing are visible in Figs. 8a and $8 \mathrm{~d}$ on regional scales-for example, in the Weddell Sea (where E21 IPSL is warmer than E21 HADLEY) and over the Southern Ocean near the date line at about $60^{\circ} \mathrm{S}$ (where E21 IPSL is cooler than E21 HADLEY). These differences tend to be reflected in the SLP fields (Figs. 8b and $8 \mathrm{e}$ ) in terms of collocated differential thermal lows and highs. These, in turn, lead to differences in the advection of moist oceanic air masses toward the Antarctic coast where orographic precipitation occurs, most 


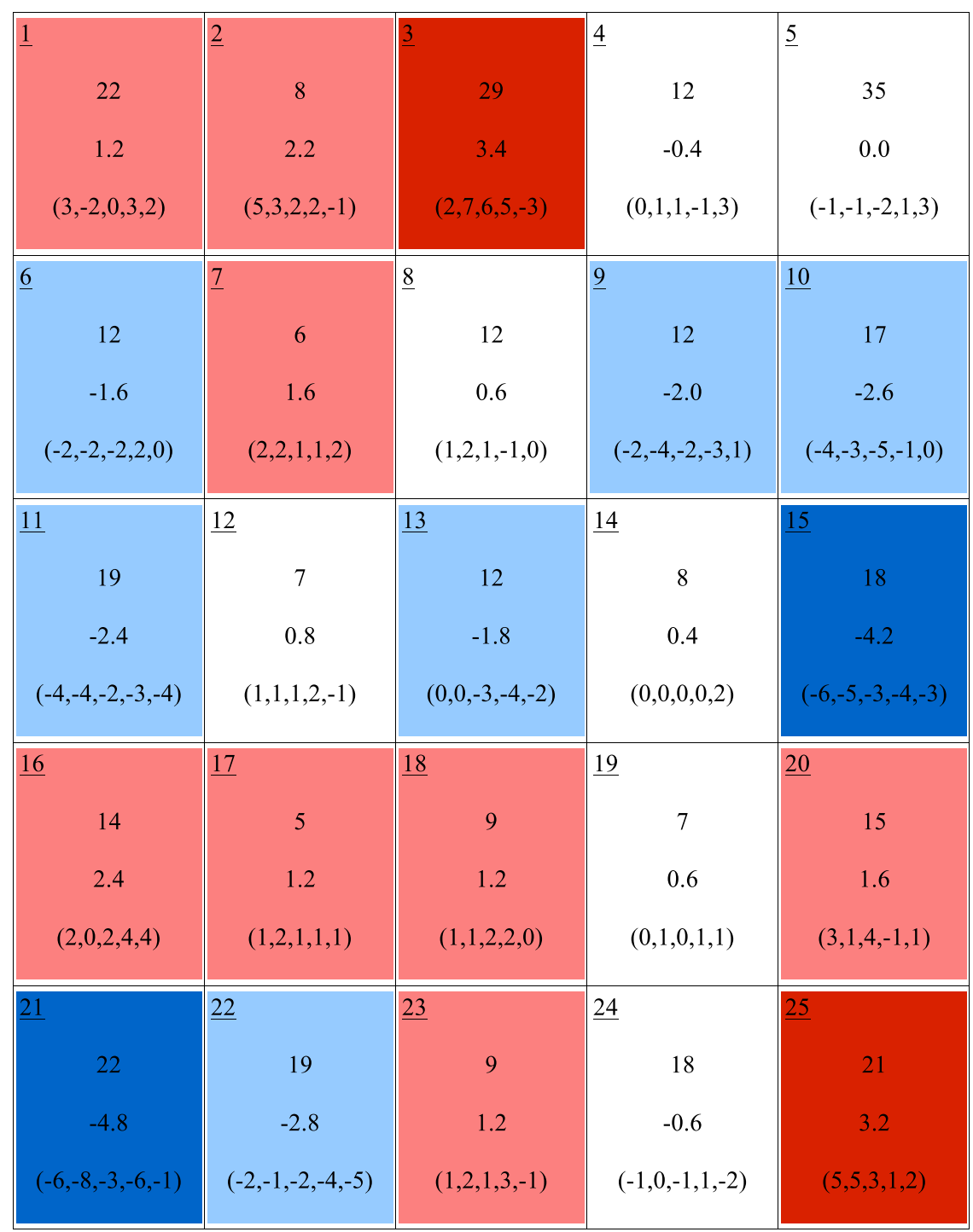

FIG. 6. Frequencies $\left(\right.$ day $\mathrm{yr}^{-1}$ ) of the 25 typical meteorological situations identified selforganizing maps. Top line of each cell, underlined: number of the situation as in Fig. 5 and in the text; second line: frequency in the E20 simulation; third line: average frequency change for the five E21 simulations; bottom line, in parentheses: frequency change for each of the E21 simulations (E21 $1_{\mathrm{MPI}}, \mathrm{E} 21_{\mathrm{IPSL}}, \mathrm{E} 21_{\mathrm{CNRM}}, \mathrm{E} 21_{\mathrm{MIROC}}$, and E21 $\left.1_{\mathrm{HADLEY}}\right)$. Cells are shaded according to the sign and intensity of the average frequency change $\Delta f$ for all E21 simulations given in the middle line $\left[\Delta f<-3\right.$ day yr$^{-1}$ (dark blue), $-3<\Delta f<-1$ day $\mathrm{yr}^{-1}$ (light blue), $-1<\Delta f<$ 1 day $\mathrm{yr}^{-1}$ (white), $1<\Delta f<3$ day yr ${ }^{-1}$ (light red), and $\Delta f>3$ day $\mathrm{yr}^{-1}$ (dark red)]. The situations are geometrically arranged as in Fig. 5.

clearly visible in our example (Figs. 8c and 8f) in Marie Byrd Land where a strong precipitation increase is simulated in E21 $1_{\text {HADLEY }}$, but not in E21 $1_{\text {IPSL }}$.

Regional precipitation changes can also be directly determined by SSC changes. For example, in E21 $1_{\text {IPSL }}$, oceanic cooling off Victoria Land (Fig. 8a) likely explains the precipitation decrease along the ice sheet margin in this sector (Fig. 8c) as described by Krinner et al. (2008), while the circulation changes described above explain the precipitation decrease simulated in E21 HADLEY in this region (Figs. 8e and 8f).

Although weak in absolute terms, the precipitation change in the interior of East Antarctica is fairly consistent among the different E21 simulations. The larger distance from the ocean means that influences from the larger sectors of the Southern Ocean are integrated, and this leads to a more consistent precipitation increase in the interior. However, the amplitude of the precipitation 


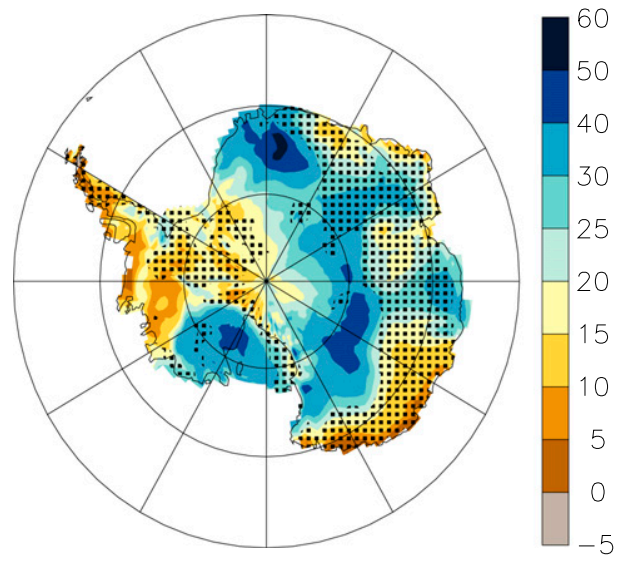

a) Relative precipitation change $\Delta \mathrm{P} / \mathrm{P}$

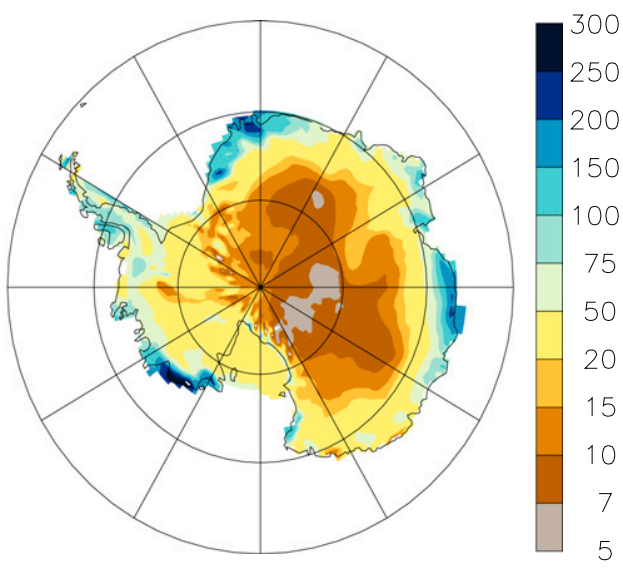

b) Absolute precipitation change DP

FIG. 7. Simulated annual-mean precipitation change with respect to E20, average over all E21 simulations. (a) Change relative to E20 (\%). Stippling identifies regions where the relative precipitation change differs by more than $50 \%$ from the ensemble average in the majority of E21 simulations. (b) Absolute average precipitation change $\left(\mathrm{kg} \mathrm{m}^{-2} \mathrm{yr}^{-1}\right)$.

increase still strongly depends on the prescribed average SSC change, as previously shown in Fig. 3.

Table 2 and Fig. 3 also show a clear link between the simulated annual-mean continental temperature and precipitation changes. The simulated sensitivity of the relative Antarctic precipitation change $\Delta P_{\mathrm{AA}} / P_{\mathrm{AA}}$ to temperature change $\Delta T_{\mathrm{AA}}$, defined as $\beta=\Delta P_{\mathrm{AA}} /\left(P_{\mathrm{AA}}\right.$ $\left.\Delta T_{\mathrm{AA}}\right)$, has been evaluated in previous studies. Gregory

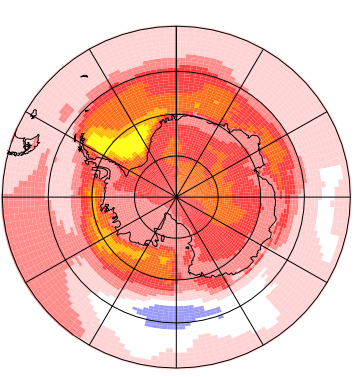

a) $\Delta \mathrm{T}_{2 \mathrm{~m}}\left(\mathrm{E} 21_{\mathrm{IPSL}}\right)$

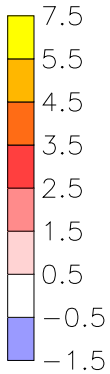

1.5

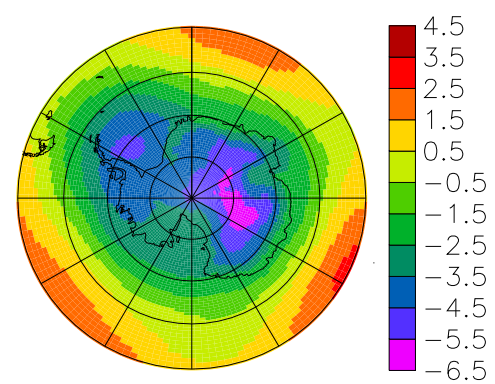

b) $\triangle \mathrm{SLP}\left(\mathrm{E} 21_{\mathrm{IPSL}}\right)$

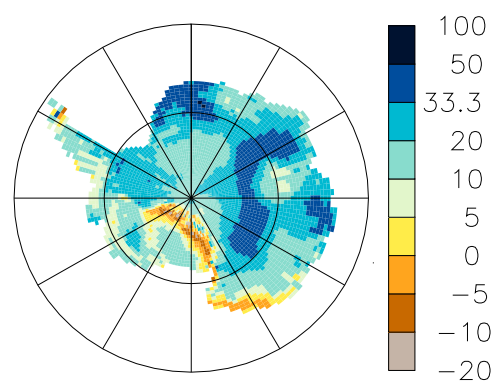

c) $\Delta \mathrm{P} / \mathrm{P}\left(\mathrm{E} 21_{\mathrm{IPSL}}\right)$

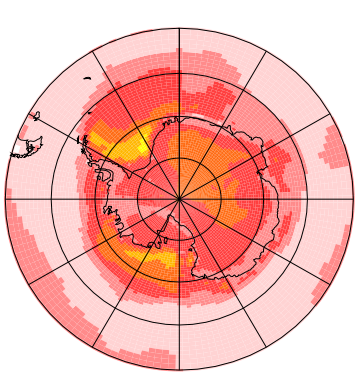

d) $\Delta \mathrm{T}_{2 \mathrm{~m}}\left(\mathrm{E} 21_{\text {HADLEY }}\right)$

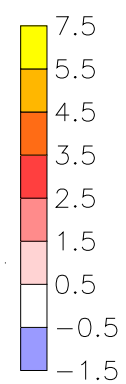

1.5

FIG. 8. Annual-mean changes with respect to E20 for two selected E21 simulations: (a)-(c) E21 IPSL and (d)-(f) E21 HADLEY for (a),(d) annual-mean surface air temperature change $\left({ }^{\circ} \mathrm{C}\right),(\mathrm{b}),(\mathrm{e})$ annual-mean SLP change (hPa), and (c),(f) relative annual-mean precipitation change $(\%)$. 
and Huybrechts (2006) give a value of $\beta=(5.1 \pm 1.5) \%$ ${ }^{\circ} \mathrm{C}^{-1}$ for a selection of CMIP3 models. Recent highresolution simulations (Krinner et al. 2007; Bengtsson et al. 2011; Ligtenberg et al. 2013) indicate values ranging from $3.7 \%$ to about $7 \%{ }^{\circ} \mathrm{C}^{-1}$. Across our E21 simulations, $\beta$ values range from $4.8 \%$ to $6.3 \%{ }^{\circ} \mathrm{C}^{-1}$ (Table 2), similar to the previous estimates. The values of $\beta$ for the supplementary simulations using the future MIROC SSC $\left(\mathrm{S}_{\mathrm{SSC} 21+\mathrm{RF} 20}: \quad \beta=7.3 \%{ }^{\circ} \mathrm{C}^{-1}\right.$ and $\mathrm{S}_{\mathrm{SSC} 21+\mathrm{RF} 21}: \beta=6.7 \%{ }^{\circ} \mathrm{C}^{-1}$ ) are a bit higher than those of the E21, but still within the range of previous estimates. Given the very weak precipitation and temperature change between $\mathrm{S}_{\mathrm{SSC} 0+\mathrm{RF} 20}$ and $\mathrm{S}_{\mathrm{SSC} 20+\mathrm{RF} 21}$, the calculated $\beta$ value for $\mathrm{S}_{\mathrm{SSC} 20+\mathrm{F} 21}\left(\beta=-0.28 \%{ }^{\circ} \mathrm{C}^{-1}\right)$ is not physically meaningful. The spatial variability of $\beta$ (not shown), with values ranging from $-6 \%$ to $+24 \%{ }^{\circ} \mathrm{C}^{-1}$, essentially reflects the effect of regional changes in atmospheric circulation patterns.

\section{d. Mechanisms of simulated precipitation changes}

The thermodynamical fraction of precipitation change $f_{\text {th }}$ clearly dominates the simulated precipitation changes over the largest parts of the Antarctic continent, as can be seen in Fig. 9. For individual E21 simulations (examples are given in Figs. 9b and 9c), $f_{\text {th }}$ is close to unity in the interior, meaning that the thermodynamical fraction almost explains the entire signal, while the dynamical fraction $f_{d}$ can be substantial in some coastal areas. This is consistent with the results presented in the preceding section that showed that changes of atmospheric circulation patterns influence the simulated coastal precipitation changes, while the precipitation changes in the interior are relatively unaffected by circulation changes. Where the precipitation change is close to 0 (typically in transition zones between regions with precipitation increase and another region where precipitation decreases), $f_{\text {th }}$ and $f_{d}$ can be large and of opposite sign because they are the result of a division by values close to 0 . Therefore, regions where the absolute value of the relative precipitation change is below $5 \%$ are masked out in Fig. 9.

The regional patterns of circulation change tend to compensate for each other if the average thermodynamical and dynamical fraction of precipitation change is calculated over the five E21 simulations, leaving the thermodynamical fraction dominant over the entire continent including the coastal areas (Fig. 9a).

\section{Discussion}

The results presented in the preceding sections give rise to several questions and remarks.

The simulated twenty-first century surface air temperature change $\Delta T_{\mathrm{AA}}$ over the Antarctic continent
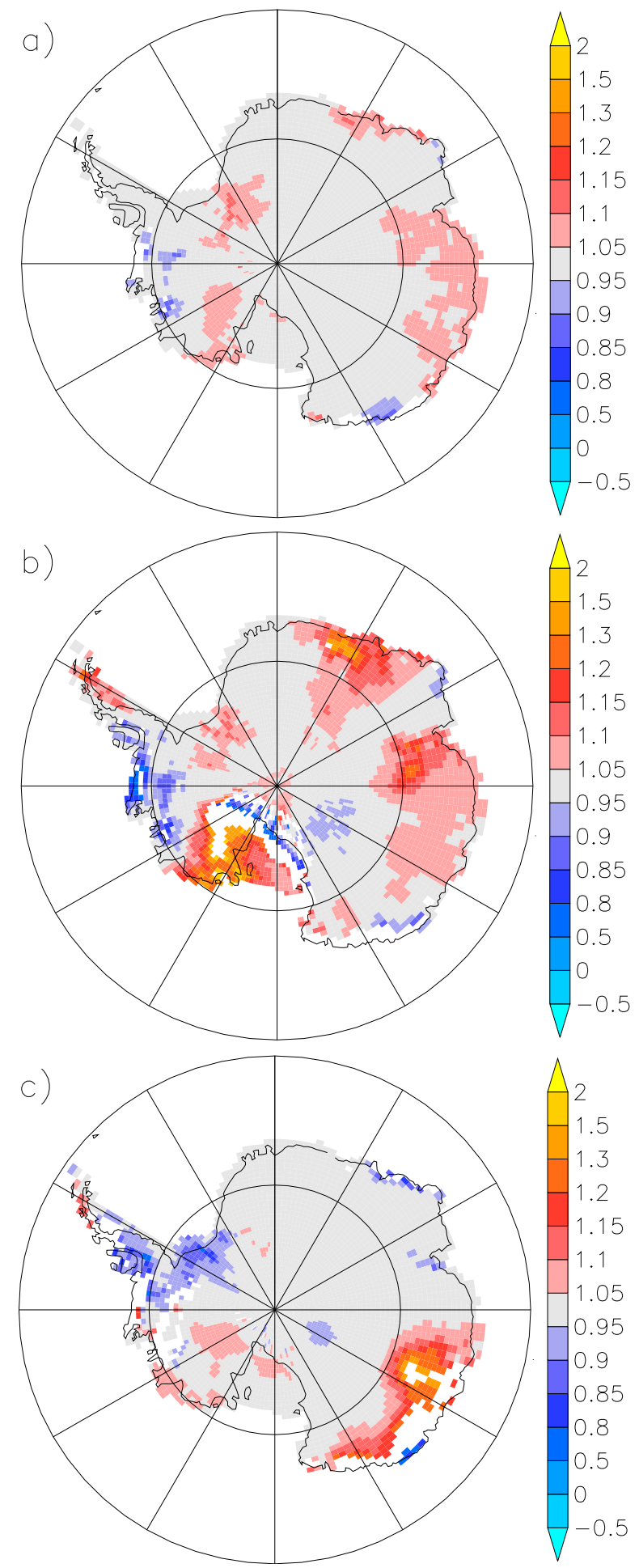

FIG. 9. Thermodynamical fraction of the annual-mean precipitation change from 1980-2007 to 2070-99 (i.e., the fraction of total precipitation change that is due to the modified average precipitation amounts linked to each of the identified 25 typical synoptic situations): (a) mean over all E21 simulations, (b) E21 IPSL, and (c) E21 HADLEY. Regions where the relative precipitation change is less than $5 \%$ are masked out. 
varies between $2.7^{\circ}$ and $4.7^{\circ} \mathrm{C}$ in our E21 simulations (Table 2). This simulated Antarctic climate change is forced by the prescribed change in oceanic boundary conditions and a prescribed modified atmospheric composition (in particular greenhouse gas concentrations). One might therefore, to first order, expect the simulated Antarctic climate change $\Delta C_{\mathrm{AA}}$ (representing the temperature change $\Delta T_{\mathrm{AA}}$ or the precipitation change $\left.\Delta P_{\mathrm{AA}}\right)$, as simulated by the AGCM, to be a linear combination of the prescribed oceanic Southern Ocean SSC change $\Delta \mathrm{SSC}_{\mathrm{SO}}$ and of a function $f(\Delta R)$ of the imposed instantaneous radiative forcing due to the atmospheric composition change: $\Delta \mathrm{C}_{\mathrm{AA}}=\kappa \Delta \mathrm{SSC}_{\mathrm{SO}}+$ $\lambda f(\Delta R)$. Because $\lambda f(\Delta R)$ is the same for all E21 simulations, we can simply write $\Delta C_{\mathrm{AA}}=\kappa \Delta \mathrm{SSC}_{\mathrm{SO}}+\mu$. Here, $\Delta \mathrm{SSC}_{\mathrm{SO}}$ can indicate a change in Southern Ocean sea surface temperature or Southern Ocean sea ice extent that is tightly linked, as mentioned before. As noted before, plotting the simulated Antarctic mean annual average climate change as a function of the prescribed SSC and atmospheric composition change for the E21 simulations (diamonds in Fig. 3) suggests that the effect of the instantaneous radiative forcing change $\mu$ is weak. Visually, this corresponds to a small intercept of a linear regression between the diamonds representing the E21 simulations in Fig. 3. This is clearly confirmed by the set of supplementary simulations using alternatively observed SSC with and without MIROC3.2(hires) SSC anomalies, and prescribed atmospheric compositions for the end of the twentieth and twenty-first centuries (red triangles, inverted triangles, and squares in Fig. 3). The simulated Antarctic climate change in simulation $\mathrm{S}_{\mathrm{SSC} 20+\mathrm{RF} 21}$ (red inverted triangles) is indeed very weak, while the simulated Antarctic climate change in simulation $\mathrm{S}_{\mathrm{SSC} 21+\mathrm{RF} 20}$ (red triangles) is similar to the simulated change in E21 MIROC. It is also similar to the simulated change in $\mathrm{S}_{\mathrm{SSC} 21+\mathrm{RF} 21}$ (red squares) because the only difference between the two simulations $\mathrm{E} 21_{\text {MIROC }}$ and $\mathrm{S}_{\mathrm{SSC} 21+\mathrm{RF} 21}$ is that $\mathrm{S}_{\mathrm{SSC} 21+\mathrm{RF} 21}$ has been carried out with a more recent model version, as stated before. This clearly shows that the simulated Antarctic climate change is almost entirely determined by the prescribed SSC change and only marginally directly influenced by the instantaneous radiative forcing due to the prescribed atmospheric composition change.

Compared to these transient climate change experiments, the relative imprint of the prescribed SSC on the simulated Antarctic climate change would certainly be even larger in equilibrium climate change simulations for a similar prescribed radiative forcing, because in this case the Southern Ocean temperature would be higher. The reason is that the Southern Ocean warms only very slowly because of deep vertical mixing (e.g., Stouffer et al. 1989).

Recent work (Racherla et al. 2012; Di Luca et al. 2013) suggests that the added value of limited area regional climate model (RCM) climate projections, obtained by using a coupled climate model to drive the RCM at its lateral boundaries, is rather limited, and that the skill of the driving coupled climate model is the most important determining factor for the quality of the projections (Racherla et al. 2012). The method used here to produce high-resolution climate change simulations by downscaling CMIP-type large-scale projections is somewhat different than the more commonly used limited-area RCM approach evaluated by Racherla et al. (2012) and Di Luca et al. (2013). The work presented here extends the RCM-specific results obtained by Racherla et al. (2012) and Di Luca et al. (2013) in the sense that it evidences a similarly strong dependence of our alternative downscaling method on the change of prescribed boundary conditions that are derived from coupled climate models. In this particular respect, the approach used here presents no distinct advantage over the use of a RCM. However, the approach has several distinct advantages that are evidenced by the results of this work. An important advantage is the fact that for the present-day control run, bias-corrected sea surface boundary conditions can be used. As shown by Krinner et al. (2008), this greatly improves the quality of the simulated present-day reference climate of the region of interest compared to simulations using direct input from a coupled climate model which is usually biased; on regional scales, coupled climate model SST biases of the same magnitude as the projected twenty-first century SST change are not unusual (Randall et al. 2007). Moreover, analyzing bias correction experiments limited to oceanic areas free of sea ice, Ashfaq et al. (2011) showed that the effects of SST bias correction on the amplitude of the simulated climate change by one AGCM are very significant and comparable to model spread across the CMIP3 ensemble. In addition, impacts of climate change generally do not depend linearly on the baseline climate; for example, warming will not lead to snowmelt if the baseline climate is affected by a strong cold bias that erroneously prevents the melting point to be attained after the warming. This is in essence the reason why climate model output in often debiased in climate change impact studies. These facts provide strong support for using bias corrections in climate change projections. Another important advantage is a high computational efficiency: a single present-day reference simulation, using observed oceanic boundary conditions, can be used in combination with a large ensemble of simulations of future climate, as 
done here with our ensemble of five E21 simulations. In RCM simulations forced by typically 6-hourly threedimensional atmospheric boundary conditions from forcing global models, a specific present-day reference run has to be carried out for each forcing model.

Using the anomaly method in a variable resolution AGCM as done here, it would furthermore be easy to produce an "average" projection based on average SSC change from a large ensemble of CMIP-type simulations. Such an approach could be particularly interesting because, as shown before, the simulated climate change on regional (i.e., continental) scales largely depends on the prescribed SSC change. However, multimodel average SSC would probably exhibit zonally rather uniform SST and sea ice change patterns. Therefore a projection forced by a multimodel average SSC change would not exhibit more realistic spatial patterns in the coastal regions than a projection forced by SSC taken from a single coupled climate model; rather, it would probably exhibit an unrealistically low horizontal variability of the climate change signal in coastal regions.

Another question raised by the results reported here concerns the use of a set of bias-corrected projections, such as our set of five E21 simulations. As shown above (section 3d), the average of such a set, if analyzed in terms of physical mechanisms, might lead to erroneous conclusions. For example, if the average precipitation change of the five E21 simulations is used, the dynamical fraction of precipitation change is nonnegligible (more than $5 \%$ ) only on $24 \%$ of the Antarctic area, while it is nonnegligible on larger parts of the Antarctic in almost all the individual E21 simulations (except E21 ${ }_{\text {MIROC }}$ ), with an average of $35 \%$. High values of the dynamical fraction of local precipitation change in one E21 simulation can be caused by the finescale spatial pattern of the external SSC forcing or by internal variability. By construction, the spatial patterns of SSC forcing are specific to each E21 simulation, and the internal variability of the atmosphere is also unlikely to produce the same geographic pattern of the dynamical fraction of precipitation change in two independent E21 simulations. Although the approach used here (involving different oceanic boundary conditions) is different from the usual ensemble approach consisting of a set of simulations using the same boundary conditions, but varying initial conditions, similar caveats therefore apply concerning the analysis of properties emerging from temporal and spatial variability.

In any case, this variable-resolution AGCM approach loosens constraints on the choice of the forcing model that exist for the more classical RCM downscaling approach, which requires an a priori selection of forcing models based on the quality of the simulated present circulation patterns on the regional scale (Fettweis et al. 2012). In addition, because no lateral atmospheric boundary conditions are required, the stretched-grid approach allows for self-consistent interactions between the region of interest and the exterior (Fox-Rabinovitz et al. 2006, 2008). In the context of climate change experiments, this means in particular that the simulated circulation changes are consistent across a wide range of spatial scales.

As shown before, the simulated Antarctic precipitation changes are essentially due to the thermodynamical contribution $\Delta_{\mathrm{th}}$, as opposed to the "dynamical" contribution $\Delta_{d}$. The precipitation change is not dominated by changes of the frequencies of any particular synoptic situation, but by the modified average precipitation amounts linked to each of the identified typical synoptic situations. This is consistent with findings presented by Uotila et al. (2007) for CMIP3 projections. It further confirms and spatially extends results presented by Emori and Brown (2005) for a subset of the CMIP3 models; the work of Emori and Brown (2005) excluded a large part of Antarctica because their analysis was based on the correlation between daily $500-\mathrm{hPa}$ vertical velocity and precipitation rates, which is low over polar regions because precipitation from low clouds is dominant.

\section{Conclusions}

Using a variable-resolution AGCM for climate change projections over the Antarctic, this study has shown that the effect of SST and SIE changes around Antarctica are of prime importance for the simulated twenty-first century Antarctic climate change. Southern Ocean warming (which itself is of course a long-term consequence of anthropogenic climate forcing) forces almost the entire twenty-first century warming over the continent, while the direct and immediate radiative effect of modified atmospheric composition on Antarctica's climate is weak. This means that the approach taken here is indeed a downscaling exercise in the sense that the climate change signal of the forcing model (here, the prescribed SSC change) very directly determines the continental-scale characteristics of the simulated climate change. This work therefore extends the conclusions of Krinner et al. (2008), who have shown that using bias-corrected sea surface boundary conditions leads to a much improved representation of the present-day climate in such experiments, and suggests that this approach is an efficient way to produce climate change projections and evaluate some of the associated uncertainties on regional scales. It would be very interesting to repeat this exercise with other stretched-grid 
AGCMs, such as the Action de Recherche Petite Echelle Grande Echelle (ARPEGE) model (Déqué et al. 1998), the atmospheric component of the CNRMCM coupled climate model (Salas-Mélia et al. 2005).

Concerning the simulated characteristics of climate change in Antarctica, this work confirms that changes of circulation patterns have significant effects on the simulated changes of precipitation rates in the coastal areas of the continent, but on average, the climate change signal is clearly dominated by "thermodynamical" rather than "dynamical" processes.

Acknowledgments. This work was supported by funding from the Ice2sea project from the European Union 7th Framework Programme, Grant 226375 (Ice2sea contribution number 177) and the INSU (LEFE/EVEIDAO) project Charmant. The simulations were carried out at the French national IDRIS computing centre and at the Mirage computing facility in Grenoble. This is a contribution to ANR project Vanish (ANR-07-VULN013). Comments by three anonymous reviewers helped to greatly improve the manuscript.

\section{REFERENCES}

Agosta, C., V. Favier, G. Krinner, H. Gallée, and C. Genthon, 2013 : High resolution modelling of the Antarctic surface mass balance, application for the twentieth, twenty first and twenty second centuries. Climate Dyn., 41, 3247-3260, doi:10.1007/ s00382-013-1903-9.

Ashfaq, M., C. B. Skinner, and N. S. Diffenbaugh, 2011: Influence of SST biases on future climate change projections. Climate Dyn., 36, 1303-1319, doi:10.1007/s00382-010-0875-2.

Bengtsson, L., S. Koumoutsaris, and K. Hodges, 2011: Large-scale surface mass balance of ice sheets from a comprehensive atmospheric model. Surv. Geophys., 32, 459-474, doi:10.1007/ s10712-011-9120-8.

Bracegirdle, T. J., W. M. Connolley, and J. Turner, 2008: Antarctic climate change over the twenty first century. J. Geophys. Res., 113, D03103, doi:10.1029/2007JD008933.

Cassano, J. C., P. Uotila, and A. Lynch, 2006: Changes in synoptic weather patterns in the polar regions in the twentieth and twenty-first centuries, part 1: Arctic. Int. J. Climatol., 26, 10271049, doi:10.1002/joc.1306.

Church, J. A., and Coauthors, 2013: Sea level change. Climate Change 2013: The Physical Science Basis, T. F. Stocker et al., Eds., Cambridge University Press, 1137-1216.

Connolley, W. M., 1997: Variability in annual mean circulation in southern high latitudes. Climate Dyn., 13, 745-756, doi:10.1007/ s003820050195.

Déqué, M., P. Marquet, and R. G. Jones, 1998: Simulation of climate change over Europe using a global variable resolution general circulation model. Climate Dyn., 14, 173-189, doi:10.1007/s003820050216.

Deser, C., R. Tomas, M. Alexander, and D. Lawrence, 2010: The seasonal atmospheric response to projected arctic sea ice loss in the late twenty-first century. J. Climate, 23, 333-351, doi:10.1175/2009JCLI3053.1.
Di Luca, A., R. de Elia, and R. Laprise, 2013: Potential for small scale added value of RCM's downscaled climate change signal. Climate Dyn., 40, 601-618, doi:10.1007/s00382-012-1415-z.

Emori, S., and S. J. Brown, 2005: Dynamic and thermodynamic changes in mean and extreme precipitation under changed climate. Geophys. Res. Lett., 32, L17706, doi:10.1029/2005GL023272.

Fettweis, X., B. Franco, M. Tedesco, J. H. van Angelen, J. T. M. Lenaerts, M. R. van de Broeke, and H. Gallée, 2012: Estimating Greenland Ice Sheet surface mass balance contribution to future sea level rise using the regional atmospheric climate model MAR. Cryosphere Discuss., 6, 3101-3147, doi:10.5194/tcd-6-3101-2012.

Fox-Rabinovitz, M., J. Côté, B. Dugas, M. Déqué, and J. L. McGregor, 2006: Variable resolution general circulation models: Stretched-Grid Model Intercomparison Project (SGMIP). J. Geophys. Res., 111, D16104, doi:10.1029/ 2005JD006520.

$-,-\longrightarrow,-,-$, and A. Belochitski, 2008: StretchedGrid Model Intercomparison Project: Decadal regional climate simulations with enhanced variable and uniform-resolution GCMs. Meteor. Atmos. Phys., 100, 159-178, doi:10.1007/ s00703-008-0301-z.

Genthon, C., G. Krinner, and H. Castebrunet, 2009: Antarctic precipitation and climate-change predictions: Horizontal resolution and margin vs. plateau issues. Ann. Glaciol., 50, 55-60, doi:10.3189/172756409787769681.

Gregory, J. M., and P. Huybrechts, 2006: Ice-sheet contributions to future sea-level change. Philos. Trans. Roy. Soc., 364A, 17091731, doi:10.1098/rsta.2006.1796.

Hourdin, F., and Coauthors, 2006: The LMDZ4 general circulation model: Climate performance and sensitivity to parametrized physics with emphasis on tropical convection. Climate Dyn., 27, 787-813, doi:10.1007/s00382-006-0158-0.

Kohonen, T., 2001: Self-Organizing Maps. Springer Series in Information Sciences, Vol. 30, Springer, $501 \mathrm{pp}$.

Krinner, G., C. Genthon, Z.-X. Li, and P. Le Van, 1997: Studies of the Antarctic climate with a stretched-grid general circulation model. J. Geophys. Res., 102, 13731-13745, doi:10.1029/ 96JD03356.

, O. Magand, I. Simmonds, C. Genthon, and J.-L. Dufresne, 2007: Simulated Antarctic precipitation and surface mass balance at the end of the 20th and 21 st centuries. Climate Dyn., 28, 215-230, doi:10.1007/s00382-006-0177-x.

— B. Guicherd, K. Ox, C. Genthon, and O. Magand, 2008: Influence of oceanic boundary conditions in simulations of Antarctic climate and surface mass balance change during the coming century. J. Climate, 21, 938-962, doi:10.1175/2007JCLI1690.1.

Ligtenberg, S. R. M., W. J. van de Berg, M. R. van den Broeke, J. G. L. Rae, and E. van Meijgaard, 2013: Future surface mass balance of the Antarctic ice sheet and its influence on sea level change, simulated by a regional atmospheric climate model. Climate Dyn., 41, 867-884, doi:10.1007/s00382-013-1749-1.

Nakicenovic, N., and Coauthors, 2000: Special Report on Emissions Scenarios. Cambridge University Press, 599 pp. [Available online at http://www.grida.no/climate/ipcc/emission/.]

Racherla, P. N., D. T. Shindell, and G. S. Faluvegi, 2012: The added value to global model projections of climate change by dynamical downscaling: A case study over the continental U.S. using the GISS-ModelE2 and WRF models. J. Geophys. Res., 117, D20118, doi:10.1029/2012JD018091.

Randall, D. A., and Coauthors, 2007: Climate models and their evaluation. Climate Change 2007: The Physical Science Basis, S. Solomon et al., Eds., Cambridge University Press, 589-662. 
Rayner, N. A., D. E. Parker, E. B. Horton, C. K. Folland, L. V. Alexander, D. P. Rowell, E. C. Kent, and A. Kaplan, 2003: Global analyses of sea surface temperature, sea ice, and night marine air temperature since the late nineteenth century. J. Geophys. Res., 108, 4407, doi:10.1029/2002JD002670.

Salas-Mélia, D., F. Chauvin, M. Déqué, H. Douville, J. F. Gueremy, P. Marquet, S. Planton, J. F. Royer, and S. Tyteca, 2005: Description and validation of the CNRM-CM3 global coupled model. CNRM working note 103, 36 pp. [Available online at http://www.cnrm.meteo.fr/scenario2004/ references_eng.html.]

Shindell, D. T., and G. A. Schmidt, 2004: Southern Hemisphere climate response to ozone changes and greenhouse gas increases. Geophys. Res. Lett., 31, L18209, doi:10.1029/2004GL020724.

Stouffer, R. J., S. Manabe, and K. Bryan, 1989: Interhemispheric asymmetry in climate response to a gradual increase of atmospheric $\mathrm{CO}_{2}$. Nature, 342, 660-662, doi:10.1038/342660a0.
Taylor, K. E., R. J. Stouffer, and G. A. Meehl, 2009: A summary of the CMIP5 experiment design. [Available online at http:// cmip-pcmdi.llnl.gov/cmip5/experiment_design.html.]

Uotila, P., A. H. Lynch, J. J. Cassano, and R. I. Cullather, 2007: Changes in Antarctic net precipitation in the 21st century based on Intergovernmental Panel on Climate Change (IPCC) model scenarios. J. Geophys. Res., 112, D10107, doi:10.1029/ 2006JD007482.

Vizcaino, M., U. Mikolajewicz, M. Groger, E. Maier-Reimer, G. Schurgers, and A. Winguth, 2008: Long-term ice sheetclimate interactions under anthropogenic greenhouse forcing simulated with a complex Earth System Model. Climate Dyn., 31, 665-690, doi:10.1007/s00382-008-0369-7.

,-- J. Jungclaus, and G. Schurgers, 2010: Climate modification by future ice sheet changes and consequences for ice sheet mass balance. Climate Dyn., 34, 301-324, doi:10.1007/ s00382-009-0591-y. 